\title{
EGF-induced proliferation of adult human pancreatic duct cells is mediated by the MEK/ERK cascade
}

\author{
Claude Rescan ${ }^{1}$, Stéphanie Le Bras ${ }^{1}$, Véronique H Lefebvre ${ }^{1}$, Ulrik Frandsen ${ }^{1}$, Tino Klein ${ }^{1}$, \\ Marco Foschi ${ }^{2}$, Daniel G Pipeleers ${ }^{1}$, Raphael Scharfmann ${ }^{1}$, Ole D Madsen ${ }^{1}$ and \\ Harry Heimberg ${ }^{1}$
}

${ }^{1}$ The JDRF Center for Beta Cell Therapy in Europe and ${ }^{2}$ Department of Internal Medicine, University of Florence, Italy

\begin{abstract}
Human postnatal pancreatic duct cells are a potential source of new beta cells. Factors regulating proliferation of human pancreatic duct cells in vitro are unknown. In several other cell types, this process is influenced by ligands of the ErbB receptor family. The expression and functionality of the ErbB family members and their possible role in duct cell proliferation were determined. In cultured adult human pancreatic duct cells the different members of the ErbB family (ErbB1-4) were present at transcript and protein level. Stimulation of the duct cells with epidermal growth factor (EGF) and betacellulin results in Tyr-phosphorylation of ErbB1 and ErbB2, followed by activation of Shc, MEK1/2 and ERK1/2. Duct cells with activated ErbB signaling changed morphology and motility. EGF induced proliferation of a fraction of the duct cells and treatment with PD98059 prevented Ki67 expression in EGF-supplemented cells. When transduced with recombinant adenovirus expressing constitutively activated MEK1, duct cells proliferate and spread even in the absence of EGF. Importantly, the adult human duct cells retain their capacity to recapitulate ngn3-induced embryonic (neuro)endocrine differentiation after proliferation. Therefore, the present data support a possible role for human adult pancreatic duct cells, following expansion and transdifferentiation, as a source of insulin by transplantation to type I diabetes patients.
\end{abstract}

Laboratory Investigation (2005) 85, 65-74, advance online publication, 15 November 2004; doi:10.1038/labinvest.3700204

Keywords: human pancreas; duct cells; EGF; proliferation; MAP kinase

Islet transplantation is currently the most promising treatment of type I diabetes ${ }^{1}$ but there is a critical limitation in the availability of insulin-producing tissue. Therefore, generation of new beta cells in vitro is a high priority issue in diabetes research. New beta cells may be generated from adult pancreatic duct cells. ${ }^{2-4}$ Human postnatal duct cells were reprogrammed to insulin-producing cells after adenovirus-mediated delivery of the neurogenin 3 gene. ${ }^{5}$ Thus, duct cells could potentially be a source of insulin-producing cells. In addition, the duct cells represent more than $30 \%$ of the human pancreas, compared to only $1-2 \%$ endocrine cells. If proliferation of this large cell number could be

Correspondence: Dr H Heimberg, PhD, Diabetes Research Center, Brussels Free University-VUB, Laarbeeklan 103, Brussels, Belgium.

E-mail: Harry.Heimberg@vub.ac.be

Received 5 April 2004; revised 6 October 2004; accepted 7

October 2004; published online 15 November 2004 controlled prior to induction of transdifferentiation to beta cells, an increased number of transplantations would be made possible. Therefore, understanding the mechanisms that regulate proliferation of human duct cells is of importance. Hepatocyte growth factor (HGF) ${ }^{6}$ and fibroblast growth factor 7 $\left(\right.$ FGF7) ${ }^{2}$ stimulate proliferation of adult human pancreatic duct cells and epidermal growth factor (EGF) appears active in pancreas ${ }^{7}$ but the mechanisms of action remain unclear. Analysis of the mechanism of receptor tyrosine kinase activation in human pancreatic duct cells may identify soluble factors that control proliferation. The present work focuses on the expression and the activity of the epidermal growth factor receptor (ErbB) family in human pancreatic adult duct cells and compares their effects with those reported for FGF7. ${ }^{2}$ Signaling of EGF and betacellulin (BTC) was examined with an emphasis on the family of MAP kinases, serine threonine-kinases that drive mitogenesis in many cell types. ${ }^{8,9}$ This study provides evidence for 
a critical role of the MEK/ERK pathway in the direct effect of EGF and BTC on controlling proliferation of adult human duct cells in vitro.

\section{Materials and methods}

\section{Adult Human Duct Cell Isolation and Culture}

Adult human pancreases from heart-beating cadaver donors were procured by European hospitals affiliated with the Eurotransplant Foundation (Leiden, Netherlands) and with Beta Cell Transplant, a multicenter program involving beta cell transplantation in type I diabetic patients. The range of adult donor ages was 11-64 years (mean \pm s.e.m.: $44 \pm 11$ ). The duct cells in this study were retrieved from the pellet following ficoll gradient density. Immediately after isolation, the exocrine cell preparation was composed of $55-65 \%$ acinar cells, $30-40 \%$ CK19positive duct cells and less than $5 \%$ endocrine cells. The exocrine cells were cultured in suspension (Ham's F10, 1\% BSA, $7.5 \mathrm{mmol} / \mathrm{l}$ glucose, $50 \mu \mathrm{g} / \mathrm{ml}$ streptomycin, $50 \mathrm{U} / \mathrm{ml}$ penicillin and $2 \mathrm{mmol} / \mathrm{l} \mathrm{L-}$ glutamine) at $37^{\circ} \mathrm{C}$ in a humidified atmosphere of $5 \% \mathrm{CO}_{2}$. During 5 days of culture, the number of acinar cells decreased considerably, as described by Heimberg et al. ${ }^{10}$ The clustered cells were then allowed to adhere on human fibronectin-coated dishes $\left(2 \mu \mathrm{g} / \mathrm{cm}^{2}\right)$ in DMEM/F12, $50 \mu \mathrm{g} / \mathrm{ml}$ streptomycin, $50 \mathrm{U} / \mathrm{ml}$ penicillin. After $24 \mathrm{~h}$, the medium was supplemented with cholera toxin $(0.1 \mu \mathrm{g} / \mathrm{ml}$; Sigma, St Louis, MO, USA) and ITS (insulin (10 $\mu \mathrm{g} /$ $\mathrm{ml})$, transferrin $(0.55 \mathrm{mg} / \mathrm{ml})$ and sodium selenite $(6.7 \mathrm{mg} / \mathrm{ml})$, Gibco Life Technologies, Rockville, MD, USA). Cell cultures were stimulated by addition of EGF $(25 \mathrm{ng} / \mathrm{ml})$, FGF7 $(25 \mathrm{ng} / \mathrm{ml})$ or BTC (1 nM) (all from R\&D Systems, Minneapolis, MN, USA). The MEK inhibitor, PD98059 (Calbiochem, San Diego, CA, USA), was dissolved in DMSO $(0.1 \%)$ and used at the concentration of $30 \mu \mathrm{M}$. Control cells were in $0.1 \%$ DMSO. Every other day, culture medium was changed.

\section{RT-PCR}

cDNA was synthesized from $2 \mu \mathrm{g}$ of RNA extracted at the end of the suspension stage and samples were diluted to the same final concentration. PCR was performed for 27 cycles. The PCR primers were designed to human sequences of EGFR, c-erbB2, cerbB3, c-erbB4. Primers specifically amplified EGFR (215 bp, 1188-1403 in NM005228), 5'cagctatgagat ggaggaag (forward), 5'ggaggagtatgtgtgaagga (reverse); C-erbB2 (193 bp, 1039-1232 in NM004448); 5'actgc ctgtccctacaacta (forward), 5'atattggcactggtaactgc (reverse); c-erbB3 (250 bp 482-732 in NM01982), $5^{\prime}$ tccttcaccactatctcagc (forward), 5'cagaacaagacctcata gcc (reverse); c-erbB4 (310 bp, 287-597 in NM 005235), 5'gctacgtgttagtggctctt (forward), 5'acgtccac atcctgaactac (reverse). The other primers have been previously described. ${ }^{5}$ Two primers (c-erbB2 forward, c-erbB4 reverse) span exon-intron boundaries and each primer set generates amplicons that span at least one intron. Amplicons were of predicted size. The primer sequences discriminate between the different members of the EGFR family. The primers that annealed to cDNA made of transcripts encoding Pax4, Nkx2.2, chromogranin A, synaptophysin, insulin, mouse ngn 3 and beta actin were described before. ${ }^{5}$ The DNA ladder used here is the $1 \mathrm{~Kb}+$ (Invitrogen, Frederik, MD, USA). The reactions were analyzed in $1.5 \%$ agarose gel containing SYBR Gold (Molecular Probes, Eugene, OR, USA) and visualized using a PhosphoImager (Molecular Dynamics, Sunnyvale, CA, USA).

\section{Immunoprecipitation and Immunoblot}

Following 5 days of culture in suspension, duct cells were incubated for $2 \mathrm{~h}$ in BSA-free medium and then exposed to EGF for 5, 10 or $30 \mathrm{~min}$, washed twice in ice-cold PBS and snap-frozen in liquid nitrogen. Cell pellets were homogenized in RIPAbuffer $(150 \mathrm{mM} \mathrm{NaCl}, 1 \%$ Nonidet P-40 (NP-40), $0.5 \%$ deoxycholate, $0.1 \%$ SDS and $50 \mathrm{mM}$ Tris-HCl $\mathrm{pH}$ 8.0), supplemented with phosphatase inhibitors ( $100 \mathrm{mM}$ sodium fluoride, $10 \mathrm{mM}$ sodium pyrophosphate, $1 \mathrm{mM}$ sodium vanadate) and protease inhibitors $(1 \mathrm{mg} / \mathrm{ml}$ leupeptin, $1 \mathrm{mg} / \mathrm{ml}$ antipain, $1 \mathrm{mg} /$ $\mathrm{ml}$ benzamidine, $5 \mathrm{mg} / \mathrm{ml}$ trypsin inhibitor, $1 \mathrm{mg} / \mathrm{ml}$ chymostatin, $1 \mathrm{mg} / \mathrm{ml}$ pepstatin $A$ and $0.5 \mathrm{mM}$ phenylmethylsulfonylfluoride), and solubilized at $4^{\circ} \mathrm{C}$. Cells cultured as monolayers were harvested in Reporter Lysis buffer (Promega, Madison, WI, USA) with Phosphatase Inhibitor Cocktail Set II (Calbiochem).

In all, $25-50 \mu \mathrm{g}$ of total cellular protein, as determined by the micro-BCA assay (Pierce, Rockford, USA), was separated on SDS-polyacrylamide gel and electroblotted. For immunoprecipitation, $250 \mu \mathrm{g}$ of protein was solubilized in RIPA buffer containing phosphatase and protease inhibitors and incubated for $16 \mathrm{~h}$ at $4^{\circ} \mathrm{C}$ in the presence of antibody. Protein A or G sepharose beads were added for $1 \mathrm{~h}$ at $4{ }^{\circ} \mathrm{C}$ and immunoprecipitates were analyzed on immunoblots of SDS-polyacrylamide gels.

Protein blots were incubated with primary antibodies for $16 \mathrm{~h}$ at $4^{\circ} \mathrm{C}$. Peroxidase-coupled secondary antibody was incubated for $1 \mathrm{~h}$. Peroxidase activity was detected by chemiluminescence (ECL, Amersham, Bucks, UK). Antibodies against activated EGF receptor, ErbB2, Shc and PY-20 were from Transduction Laboratories (Lexington, KY, USA), Thr202/Tyr204 Phospho-ERK1/2, pan ERK1/2 Ser 473 Phospho-AKT, pan AKT, Thr183/Tyr185 Phospho-SAPK, pan SAPK, Thr180/Tyr182 Phosphop38, pan p38 were from Cell Signaling Technology (Beverly, MA, USA) and anti-EGF receptor from Santa Cruz Biotech. Molecular weight markers (Invitrogen) were used as standards. Positive sam- 
ples for phospho-P38 and phospho-SAPK were obtained from Cell Signaling Technology (Beverly, MA, USA).

\section{Immunohistochemistry and Cytochemistry}

Following suspension, culture cell clusters were fixed in $4 \%$ paraformaldehyde (PFA) for $1 \mathrm{~h}$, cryoprotected in $30 \%$ sucrose in $0.1 \mathrm{~mol} / \mathrm{l} \mathrm{PBS}$ and embedded in Tissue-Tek (Sakura Finetek Europe, The Netherlands). Seven micrometer cryosections were cut on a cryostat. The sections were rinsed in PBS, blocked with $10 \%$ donkey serum (Jackson Immuno Research, West Grove, PA, USA) and incubated overnight in the presence of primary antibodies, diluted in PBS, $0.25 \%$ BSA and $0.3 \%$ Triton X-100. The sections were washed in PBS and incubated with fluorescent secondary antibodies (Jackson Immuno Research) together with 4-diamidino-2-phenylindole (DAPI) (Merck, Darmstadt, Germany) for $1 \mathrm{~h}$, and mounted in fluorescence mounting media (Kierkegaard and Perry, Gaithersburg, MD, USA). Anti-cytokeratin 19 (CK19) (clone RCK 108) was from DAKO (Glostrup, Denmark), anti-EGFR from Zymed Laboratories (San Francisco, CA, USA), anti-ErbB3 from Novocastra Laboratories (Newcastle upon Tyne, UK) and anti-Ki67 from Neomarkers (Fremont, CA, USA). TSA amplification system (Perkin Elmer Science, Boston, MA, USA) was used for detection of Ki67.

\section{Adenoviral Infection}

Cells were incubated in small volume for $4 \mathrm{~h}$ in the presence of adenoviruses expressing ngn $3^{5}$ or the constitutive active form of $\mathrm{MEK}^{11}$ at a multiplicity of infection of 50. Adenoviruses that expressed GFP were used as control. After infection, cells were washed twice, seeded on human fibronectin-coated dishes and cultured for 10 days before analysis of proliferation and transdifferentiation.

\section{Results}

\section{The Expression Profile of ErbB Family Members in} Adult Human Pancreatic Duct Cells

Various ligands of the ErbB receptor family (EGF, HB-EGF and BTC) were transcribed in the pancreas from adult donors (data not shown). Signal transduction by these growth factors is mediated by ErbB1 (EGFR), ErbB2, ErbB3 and ErbB4. The expression profile of these receptors was investigated in human pancreatic duct cells. Transcripts encoding the 4 ErbB-receptors (Figure 1a) and ErbB1 and ErbB3 proteins (Figure 1b) were detected in duct cells.
Effect of EGFR Ligands on Morphology and Proliferation of Adult Human Pancreatic Duct Cells

Stimulation with EGF or BTC induced spreading and monolayer formation of adult human duct cells were cultured for 7 days on human fibronectin (Figure 2a). These changes were not observed when cells were treated with FGF7, which had been previously used to expand human duct cells in culture. $^{2}$

The proliferative activity in stimulated duct cells was investigated by immunostaining with an antibody that recognizes a nuclear antigen Ki-67, expressed during late G1-, S-, M-, and G2-phase of the cell cycle but not during the quiescent phase G0. Ki-67 was expressed in not only $0.3 \pm 0.2 \%$ of control- and $1.2 \pm 0.3 \%$ of FGF7-treated duct cells but also in $6.0 \pm 1.7 \%$ and $6.6 \pm 0.8 \%$ of cells treated with EGF or BTC, respectively (Figure 2b).

\section{EGF Stimulates Tyrosine Phosphorylation of ErbB1 and Downstream Signaling Proteins}

To investigate signal transduction by receptors of the ErbB family in cultured human duct cells, EGFinduced protein tyrosine phosphorylation was analyzed. Incubation of duct cells with EGF for 5, 10 or $30 \mathrm{~min}$ induced tyrosine phosphorylation of two proteins of approximately 50 and $200 \mathrm{kDa}$ (Figure $3 a)$. The $200 \mathrm{kDa}$ molecular weight phosphoprotein was recognized on immunoblot by an antibody raised against activated ErbB1 (Figure 3b). The specificity of the immunoreaction was confirmed by incubation of protein extracts from EGF-stimulated (5 min) and control duct cells with an antiErbB1 antibody, followed by immunoprecipitation, immunoblotting and incubation with antibodies that recognized either phosphotyrosine or both activated and inactived ErbB1: activated ErbB1 was immunoprecipitated in EGF-stimulated cells only (Figure 3c). Similarly, ErbB2 was phosphorylated upon EGF treatment (data not shown). The $50 \mathrm{kDa}$ molecular weight protein with EGF-induced tyrosine phosphorylation was immunoprecipitated by an Shc-specific antibody (Figure 3d).

Phosphorylation of MEK1/2 was low in nonstimulated and in FGF7-treated duct cells but strongly increased following treatment with EGF and BTC for 2-60 min (Figure 4a). ERK1/2 (p44/42 MAPK), JNK/ SAPK and p38 MAPK were all expressed in adult human duct cells but only ERK1/2 became phosphorylated by EGF and BTC (Figure $4 a$ and b). The EGF and BTC activation of ERK1/2 signaling was independent of the presence of insulin (data not shown). Activation of AKT/Protein Kinase B, an essential component of the phosphatidylinositol 3kinase signal transduction, was modified by insulin but not by the ErbB ligands (data not shown). Nerve growth factor-induced gene A was transcribed following EGF stimulation (data not shown), confirming the capacity of the EGFR family to transduce 
A
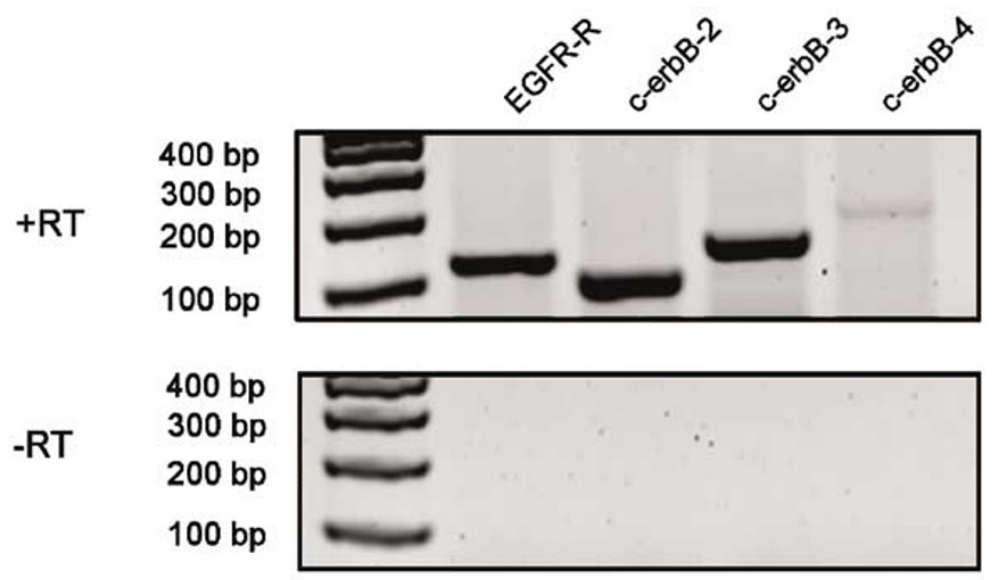

B
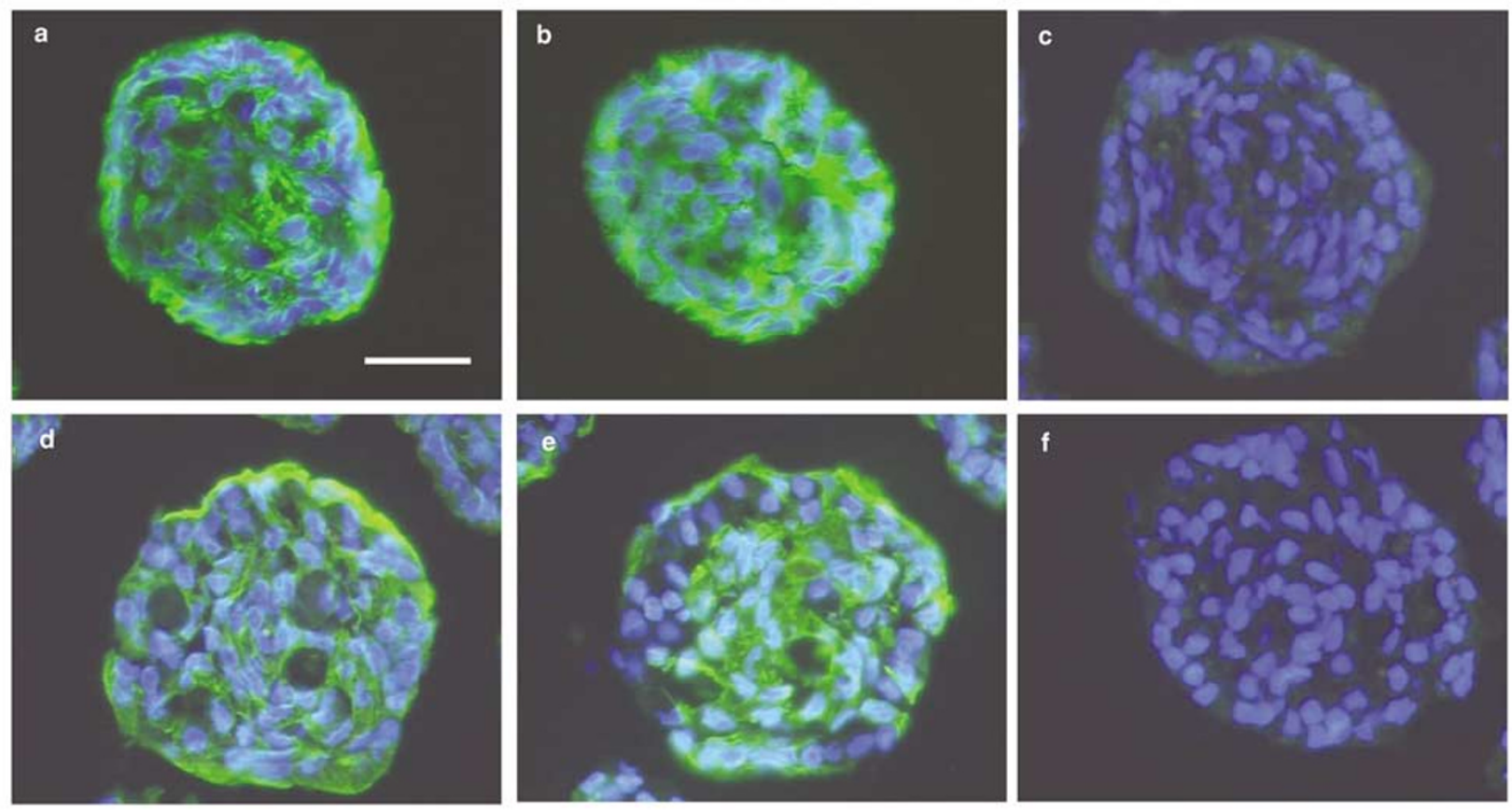

Figure 1 Expression of erb receptors in cultured adult human duct cells. (A) RT-PCR analysis of EGFR, ErbB2, ErbB3, ErbB4 expression in adult duct cells. RNA from duct cells was incubated for reverse transcription in the presence (RT +) or in the absence (RT-) of reverse transcriptase. Lane 1: $100 \mathrm{bp}$ DNA ladder. The experimental conditions were described under Materials and methods. (B) Sections of human duct cell clusters cultured for 5 days in suspension and immunostained for EGFR (a) or ErbB3 (d). Staining of the duct cell marker CK19 is shown in consecutive sections (b, e). DAPI stains all nuclei blue. On control adjacent sections (c, f) primary antibodies were omitted. Bar, $25 \mu \mathrm{m}$.

extracellular signals to the nucleus of human duct cells.

\section{ERK Activation is Necessary and Sufficient for EGF-Induced Duct Cell Proliferation and Morphological Changes}

To further evaluate the role of the MEK/ERK pathway, duct cell proliferation was examined in the presence of PD98059, a well-characterized inhibitor of MEK. ${ }^{12}$ PD98059 fully inhibited EGF-induced phosphorylation of ERK (Figure 5a) but did not change phosphorylation of Ser 473-AKT, suggesting specificity of the inhibitor for the MEK/ERK pathway.

The percentage of EGF-stimulated Ki67-expressing duct cells decreased from $8.6 \pm 0.7 \%$ in the absence to $1.6 \pm 0.4 \%$ in the presence of PD98059 (Figure 5b). BTC-induced Ki67 immunostaining was also inhibited by PD98059 (data not shown), suggesting that both EGF and BTC signal through the ERK pathway. In addition, EGF induced spreading of the duct cells in culture, which was not observed in the presence of the MEK inhibitor (Figure 5c). The effect of EGF on duct cell morpho- 
a
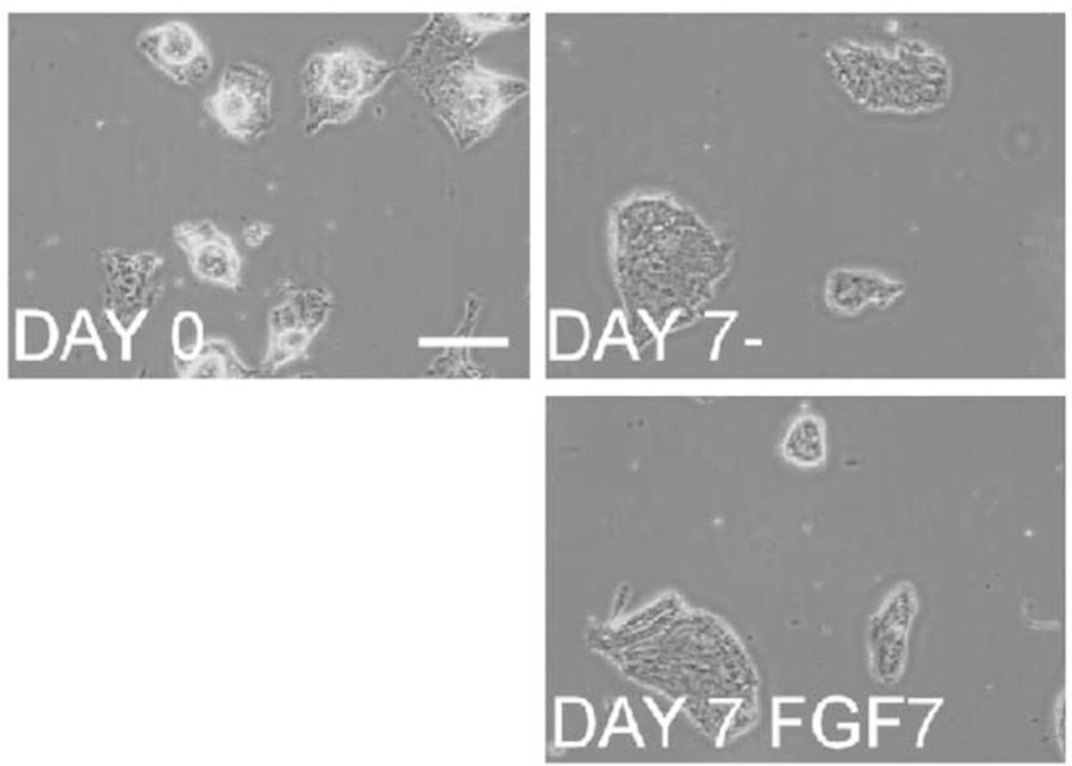

b

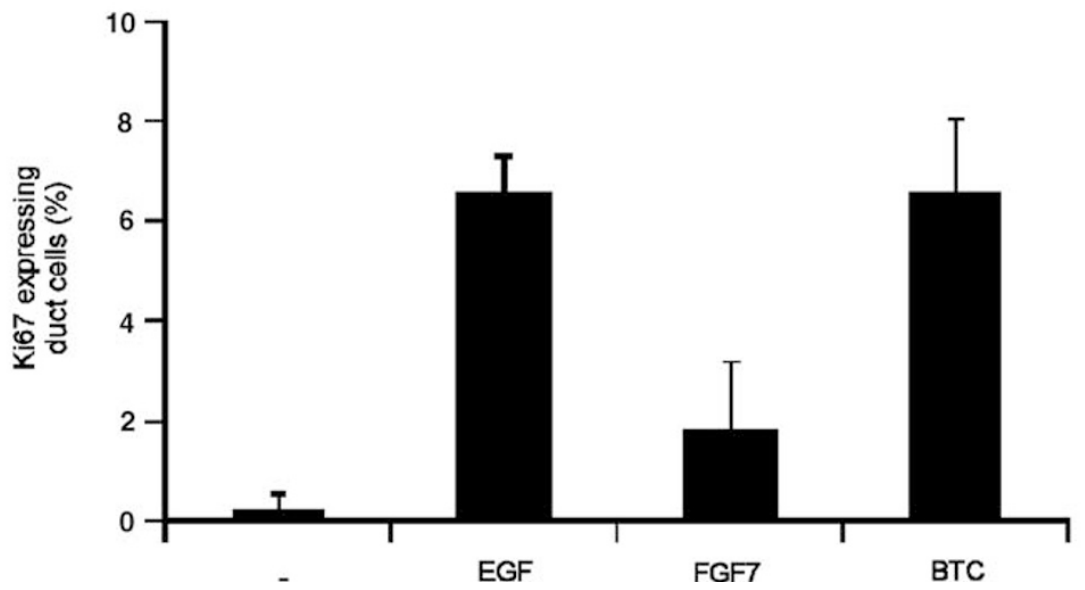

Figure 2 EGF and BTC induce morphological changes and Ki67 expression in adult human pancreatic duct cells. (a) The capacity of adult human duct cell clusters to spread on human fibronectin-coated dishes before (day 0) or after 7 days culture in media containing no growth factors, EGF, FGF7 or BTC. Bar, $200 \mu \mathrm{m}$. (b) Ki67 expression was examined in cells after 7 days of culture in medium without growth factors or supplemented with EGF, FGF7 or BTC. Fixed cells were immunostained for Ki67 and CK19. Each value represents 500 cells from at least four different pancreata. Data are expressed as mean \pm s.e.m.

logy was reversible as spreading of the cells reappeared following the withdrawal of PD98059 (data not shown).

We then explored whether MEK activation was not only needed but also sufficient to induce cell spreading and proliferation by infection of adult human duct cells with recombinant adenoviruses expressing a constitutively active form of MEK1 (AdMEKca). When infected with control virus AdGFP, duct cells spread only in the presence of EGF. However, spreading following infection with AdMEKca was independent of EGF (Figure 6a). In addition, AdMEKca induced Ki67-positivity in $6.4 \pm 0.6 \%$ of the infected duct cells, in the absence of EGF (Figure 6b) while the number of Ki67immunostained duct cells did not increase following infection with AdGFP control virus.
As we have shown previously, adult human duct cells transdifferentiate to a neuroendocrine phenotype by ectopic expression of neurogenin $3 .^{5}$ Neurogenin 3 is a master-switch transcription factor that controls embryonic development of the endocrine pancreas. ${ }^{13}$ Transduction of adult human duct cells by recombinant adenoviruses expressing neurogenin 3 -induced transdifferentiation to an identical neuroendocrine cell type as previously described, whether or not the cells were first amplified by EGF treatment. The genes encoding the developmental transcription factors, Pax4 and Nkx2.2, and the neuroendocrine marker genes, synaptophysin and chromogranin A, none of which are expressed in nontransduced adult pancreatic duct cells, were activated similarly in expanded and nonexpanded cells following ectopic neurogenin 3 


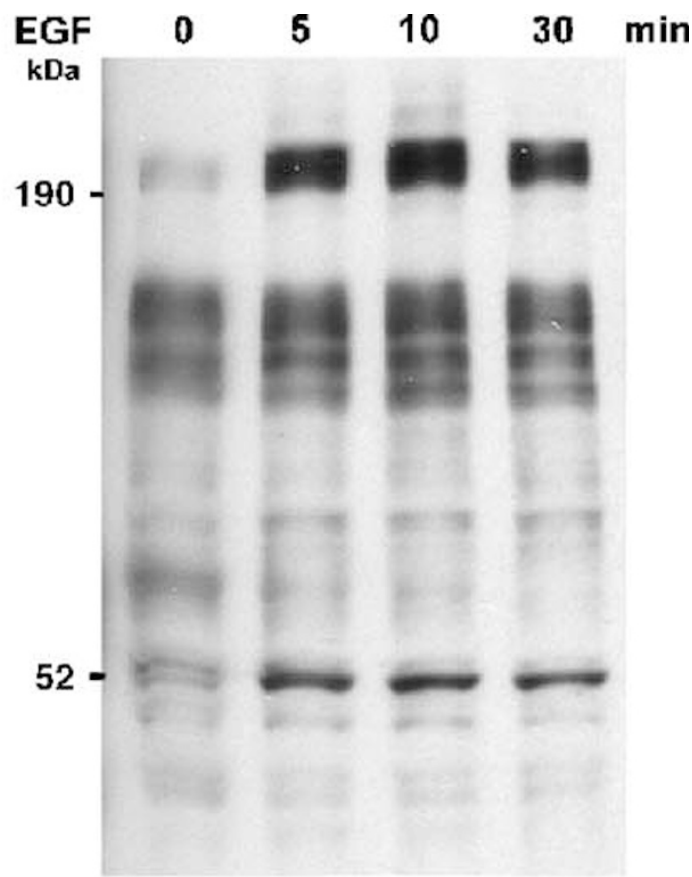

IB: PY20

b

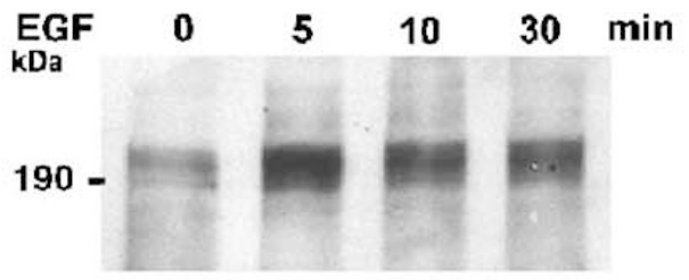

IB:phosphoEGFR

C

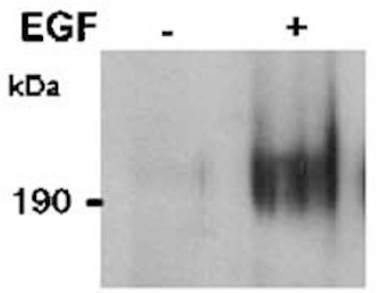

IP: EGFr

IB: PY20

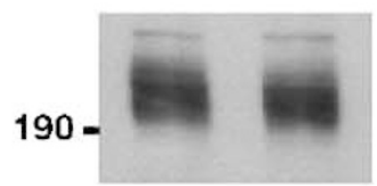

IB: EGFr

d

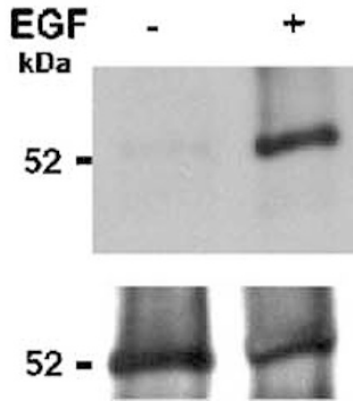

IP: Shc

IB: PY20

IB: Shc

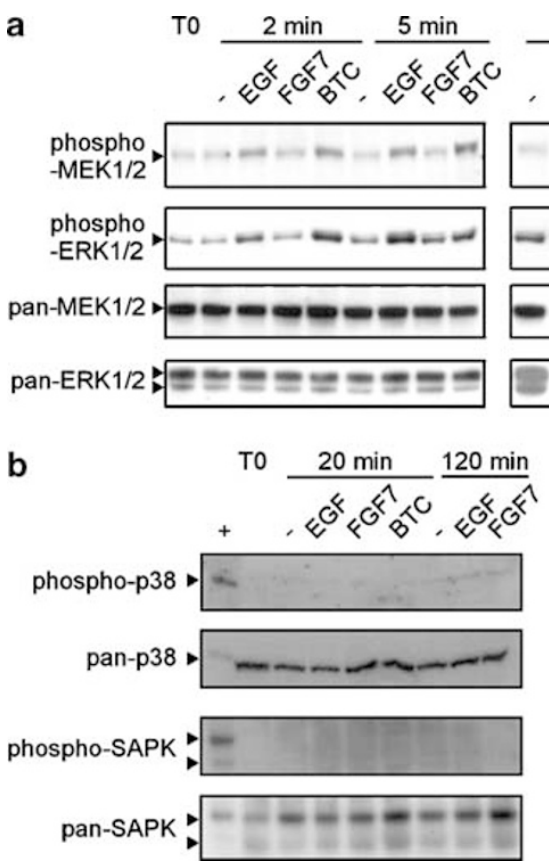

Figure 4 EGF and BTC, but not FGF7, induce phosphorylation of ERK1/2 but not of p38 MAPK or JNK/SAPK. MEK, ERK1/2, JNK/ SAPK and p38 MAPK expression and phosphorylation were examined in adult human duct cells, before (T0) and at different times after treatment without (-) or with EGF, FGF7 or BTC. Lysates were analyzed by immunoblotting. Phosphorylation or abundance of the signal transducers was detected by antibodies, specific for active or both inactive and active signaling protein. (a) Phosphorylation and expression of MEK and ERK1/2. Same lysates were used for the determination of the expression level of MEK and ERKs. (b) Phosphorylation and expression of p38 MAPK and JNK/SAPK ( + : positive control).

expression (Figure 7). As described in the original report, activation of the insulin gene by neurogenin 3 varies strongly in a donor-dependent manner. In the present duct cell preparations, infection with Ad-ngn3 induced insulin gene transcription, independent of the expansion phase, albeit at low levels.

\section{Discussion}

Despite recent remarkable findings on beta cell neogenesis in adult mice by proliferation of existing beta cells ${ }^{14}$ and on the existence of pancreatic stem/ progenitor cells among adult mouse islet- and duct

Figure 3 EGF-induced protein phosphorylation on tyrosine residues in adult human duct cells. (a, b) Duct cells were treated for $0,5,10$ and $30 \mathrm{~min}$ with EGF. The cells were lysed and proteins were separated on $8 \%$ SDS-PAGE, blotted and incubated with either an antiphosphotyrosine antibody (a) or an antiactivated EGFR (b). Duct cells were treated with EGF for $5 \mathrm{~min}$. Proteins were immunoprecipitated with (c) an anti-EGFR antibody, and immunoblots were incubated with either an antiphosphotyrosine antibody or an anti-EGFR, or (d) an anti-Shc antibody, and immunoblots were incubated with either an antiphosphotyrosine or an anti-Shc antibody. 
a

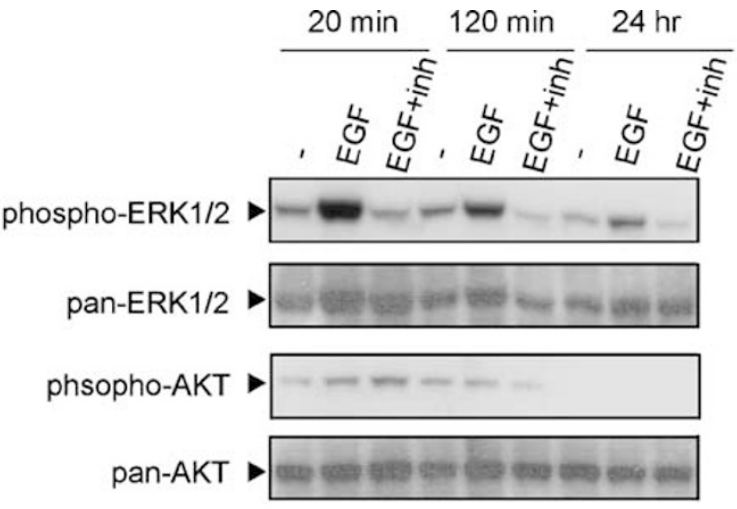

b

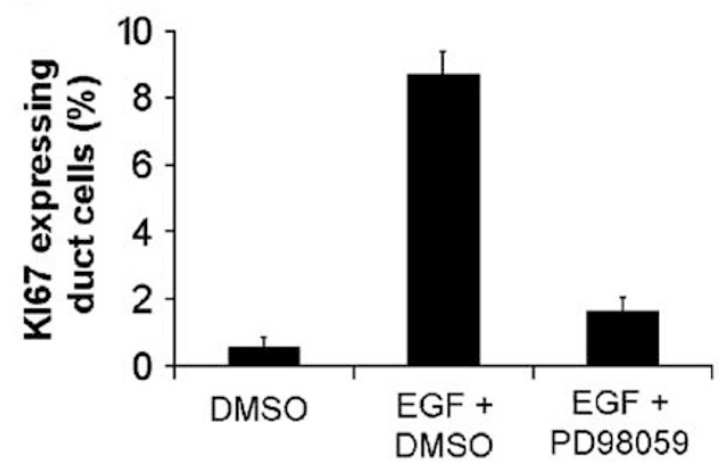

C
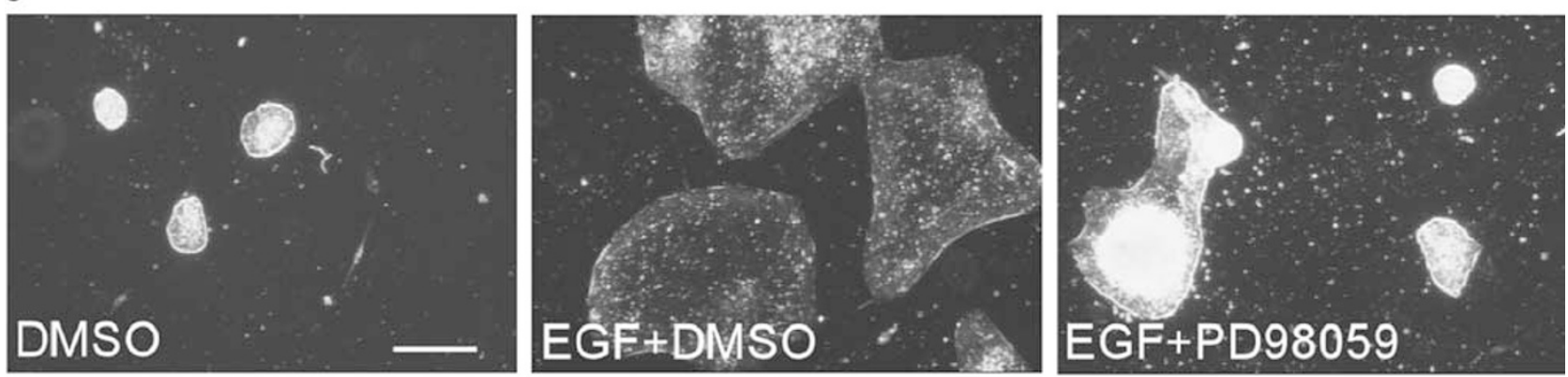

Figure 5 Effects of MEK inhibition by PD98059 on ERK phosphorylation, Ki67 expression and cell morphology. At $1 \mathrm{~h}$ following incubation in medium containing PD98059 or solvent (0.1\% DMSO) only, cells were stimulated with EGF. (a) Cells were harvested 20, $120 \mathrm{~min}$ or $24 \mathrm{~h}$ after EGF addition. A measure $20 \mu \mathrm{g}$ of cell lysate was subjected to immunoblot analyses with various antibodies. Antibodies were directed against phosphorylated or against both activated and inactive ERK1/2 and AKT. (b) Ki67 expression was examined in cells after 5 days of culture with or without EGF, in the presence or absence of PD98059. Proliferating duct cells costained for Ki67 and CK19. For each point, at least 500 cells from three different pancreata were counted. Data are expressed as mean \pm s.e.m. (c) Clusters of human duct cells were analyzed for spreading after 5 days of culture in control medium, supplemented with EGF, or with EGF and MEK inhibitor.

cells, ${ }^{15}$ very little is known about the neoformation of beta cells in the adult human pancreas. In view of the capacity of these cells to differentiate into insulin-expressing cells, ${ }^{2,5}$ the identification of factors regulating the expansion of adult human pancreatic duct cells has potential importance for the treatment of diabetes.

Receptor tyrosine kinases EGFR, HGFR, FGFR or IGF1R are involved in the proliferation of different cell types. ${ }^{16}$ Both FGF7 and HGF appear to favor growth stimulation of epithelial cells from human pancreatic ducts ${ }^{2,6}$ and EGF signaling is important for development of organs, like the pancreas, requiring epithelial-mesenchymal interaction. ${ }^{17}$ The effect of EGF on proliferation and motility of progenitor(-like) cells, other than pancreatic, has been extensively described. ${ }^{18-21}$ Moreover, EGF receptors have been detected in adult human and in developing mouse pancreatic ducts ${ }^{22-24}$ and are critical for proper pancreas development. ${ }^{25}$ The present study analyzes the expression and function of the ErbB family in cultured adult human pancreatic duct cells. Examination of the ErbB family of receptors showed that all forms of the receptor were expressed in the duct cell preparations used in this study. EGF induced phosphoryla- tion of duct cell EGFR and ErbB2, followed by activation of Shc, MEK and ERK. The MEK/ERK pathway was found necessary and sufficient to induce mitogenesis in adult human duct cells. The MEK/ERK pathway is also activated to influence proliferation of pancreatic duct cells during pancreas regeneration in RIP-IFNgamma transgenic mice by stromal cell-derived factor-1alpha ${ }^{26}$ and following overexpression of amphiregulin ${ }^{27}$ in mice.

It is important to note that in contrast to other reports on adult human duct cell proliferation,,$^{2,6,28}$ cells of the current study were cultured in defined, serum-free medium and on recombinant fibronectin. Our data suggest that cultured adult human pancreatic duct cells can proliferate under these serumfree conditions. The fraction of duct cells proliferating after stimulation with EGF or transduction with activated MEK1 was similar, suggesting that the presence of the ligand is rate limiting in this process. The rather modest percentage of proliferating duct cells observed under our culture conditions may be an inherent characteristic of the human duct cells as the age of the donor is critical for both proliferation and differentiation. Indeed, when grafted under the mouse kidney capsule, duct cellenriched fractions of the human pancreas generated 


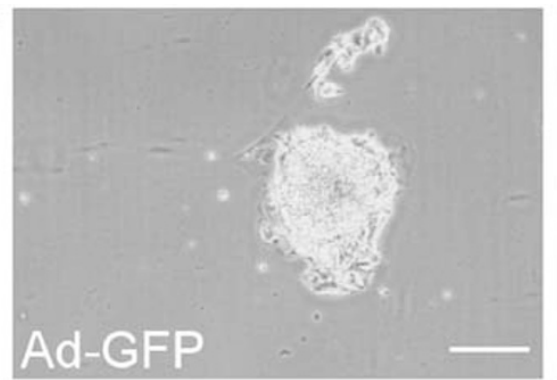

b

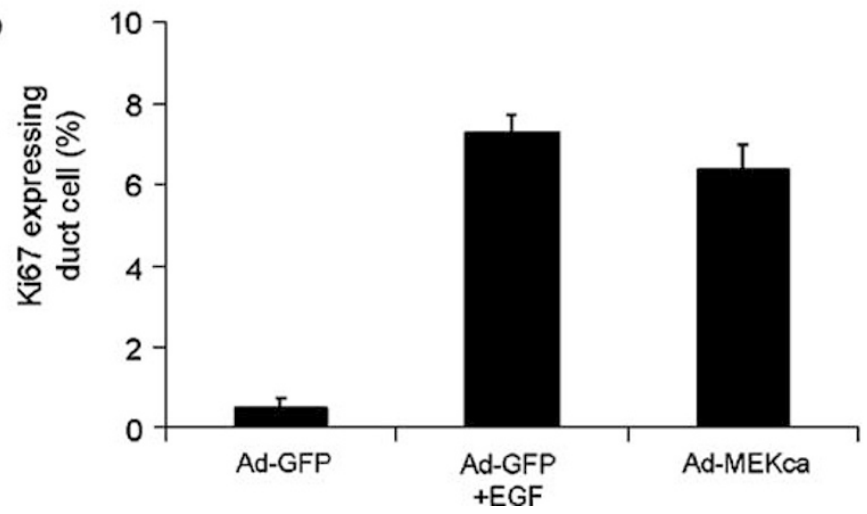

Figure 6 Expression of a constitutive form of MEK is sufficient for Ki67 expression and morphological modification of adult human duct cells. (a) Clusters of human duct cells were analyzed for spreading 5 days after adenoviral infection. Bar, $200 \mu \mathrm{m}$. (b) Ki67 expression was examined in cells cultured for 5 days following infection with adenovirus expressing GFP (Ad-GFP) or a constitutive active form of MEK (Ad-MEKca), followed by culture in the presence or absence of EGF. For each point, at least 500 cells from three different pancreata were counted. Data are expressed as mean \pm s.e.m.

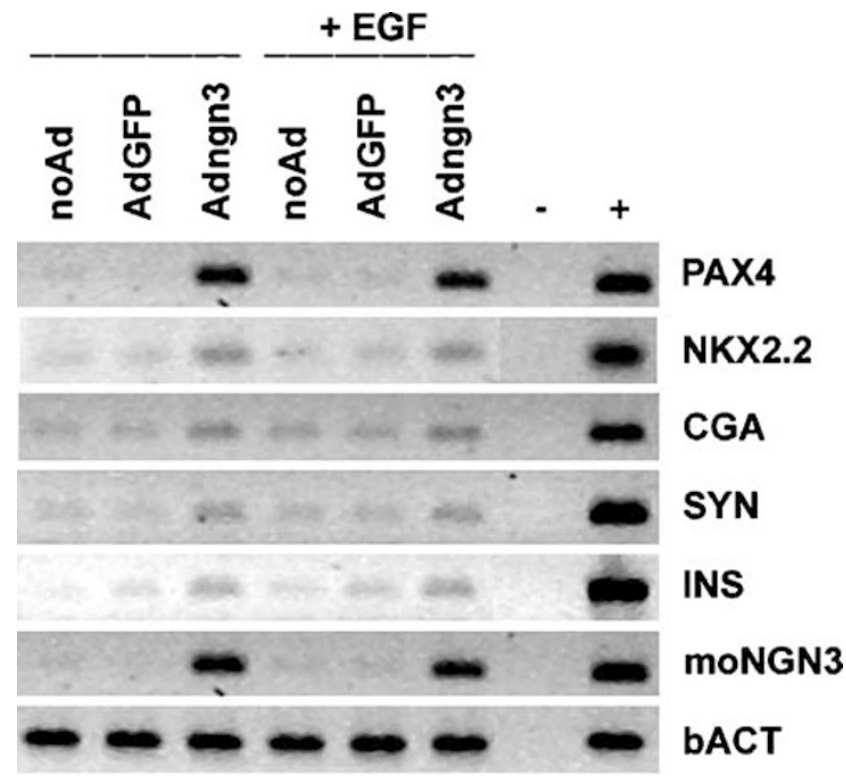

Figure 7 Effect of adenovirus-mediated ectopic expression of ngn3 on key developmental transcription factors and neuroendocrine marker expression in adult human duct cells after before and following proliferation. Gene profiling uninfected (no Ad), control-infected (Ad-GFP) and neurogenin 3-infected (Ad-ngn3) adult human duct cells, treated or not with EGF. RNA was extracted following 10 days of infection and analyzed by RT-PCR as described by Heremans et $a l^{5}$ using primer sets that specifically amplified Pax4, Nkx2.2, synaptophysin, chromogranin A, insulin, virally introduced mouse ngn3 and beta-actin. beta cells only when isolated from donors less than 10 years of age. ${ }^{29}$ Furthermore, age-related differences in membrane receptor complexes involved in signal transduction have been described. ${ }^{30,31}$ Duct cells used in the present study were from donors aged $44+11$ years and thus likely to be less sensitive to extracellular signals for proliferation or/and differentiation.

FGF7 induced increased duct cell proliferation following injection in adult $\mathrm{rat}^{32}$ or transgenic expression in mice. ${ }^{33}$ Bonner-Weir et $a l^{2}$ observed in vitro expansion of human duct tissue in the presence of fetal bovine serum and FGF7. Using an identical protocol, Gao et $a l^{34}$ reported that FGF7 has no effect on growth or differentiation of the pancreatic cells. The current study shows only a moderate effect of FGF7 on Ki67 expression in human duct cells, despite transcription of the gene encoding its receptor. ${ }^{35}$ The differential effect of FGF7 may be caused by specific experimental conditions. A processing effect by serum components cannot be excluded. Furthermore, the 2-4 weeks of duct cell culture ${ }^{2}$ may allow synthesis of additional growth and/or differentiation factors.

While MEK/ERK pathway activation has been shown to be sufficient to drive mitogenesis in many cell types ${ }^{8,9}$ the importance of MAP kinase signaling for the proliferation of human duct cells has not been analyzed before. We report that ERK1/2, JNK/ 
SAPK and p38 MAPK are expressed by adult human pancreatic duct cells. Although JNK/SAPK and p38 MAPK are not activated early following addition of EGF, our data do not exclude that their delayed activation may play a role in proliferation of human duct cells. In contrast, our data provide evidence that early activation of the MEK/ERK1/2 pathway is necessary and sufficient to drive spreading and proliferation of adult human pancreatic duct cells. This conclusion is based on the following: (i) EGFand BTC-induced Ki67 expression correlates with a rapid phosphorylation of MEK and ERK; (ii) an MEK inhibitor dramatically decreased the number of Ki67-positive duct cells and (iii) the expression of activated MEK1 is sufficient for inducing expression of Ki67. Importantly, the duct cells remain capable of recapitulating embryonic neuroendocrine differentiation following ectopic expression of neurogenin 3. Therefore, the present data support a role for duct cells, following expansion and transdifferentiation, as a source of insulin by transplantation to type I diabetes patients. The major future challenge will be to explore the limits of adult human duct cell capacity to expand and, especially, to further optimize duct-to-beta cell transdifferentiation in terms of insulin production.

\section{Acknowledgements}

This study was supported by a Juvenile Diabetes International Research Grant, the Danish Research Council, NovoNordisk A/S, the European Community (BMH4-CT98-3448) and the Juvenile Diabetes Research Foundation Center for Beta Cell Therapy in Europe. We are indebted to Dr Palle Serup for helpful discussion. HH is the recipient of a Career Development Award from the Juvenile Diabetes Research Foundation and a Post-Doctoral Research Fellowship from the Fund for Scientific ResearchFlanders, Belgium. CR, UF, TK and ODM are employed at the Hagedorn Research Institute, a basic research component owned by Novo Nordisk A/S. ODM holds employee shares in Novo Nordisk A/S.

\section{References}

1 Shapiro AM, Lakey JR, Ryan EA, et al. Islet transplantation in seven patients with type 1 diabetes mellitus using a glucocorticoid-free immunosuppressive regimen. N Engl J Med 2000;343:230-238.

2 Bonner-Weir S, Taneja M, Weir GC, et al. In vitro cultivation of human islets from expanded ductal tissue. Proc Natl Acad Sci USA 2000;97:7999-8004.

3 Bouwens L, Kloppel G. Islet cell neogenesis in the pancreas. Virchows Arch 1996;427:553-560.

4 Bouwens L, Pipeleers DG. Extra-insular beta cells associated with ductules are frequent in adult human pancreas. Diabetologia 1998;41:629-633.
5 Heremans Y, Van De Casteele M, in't Veld P, et al. Recapitulation of embryonic neuroendocrine differentiation in adult human pancreatic duct cells expressing neurogenin 3. J Cell Biol 2002;159: 303-312.

6 Lefebvre VH, Otonkoski T, Ustinov J, et al. Culture of adult human islet preparations with hepatocyte growth factor and $804 \mathrm{G}$ matrix is mitogenic for duct cells but not for beta cells. Diabetes 1998;47:134-137.

7 Seno M, Tada H, Kosaka M, et al. Human betacellulin, a member of the EGF family dominantly expressed in pancreas and small intestine, is fully active in a monomeric form. Growth Factors 1996;13:181-191.

8 Johnson GL, Lapadat R. Mitogen-activated protein kinase pathways mediated by ERK, JNK, and p38 protein kinases. Science 2002;298:1911-1912.

9 Robinson MJ, Cobb MH. Mitogen-activated protein kinase pathways. Curr Opin Cell Biol 1997;9:180-186.

10 Heimberg $\mathrm{H}$, Bouwens L, Heremans $\mathrm{Y}$, et al. Adult human pancreatic duct and islet cells exhibit similarities in expression and differences in phosphorylation and complex formation of the homeodomain protein Ipf-1. Diabetes 2000;49:571-579.

11 Foschi M, Chari S, Dunn MJ, et al. Biphasic activation of p21ras by endothelin-1 sequentially activates the ERK cascade and phosphatidylinositol 3-kinase. EMBO J 1997;16:6439-6451.

12 Alessi DR, Cuenda A, Cohen P, et al. PD 098059 is a specific inhibitor of the activation of mitogen-activated protein kinase kinase in vitro and in vivo. J Biol Chem 1995;270:27489-27494.

13 Jensen J. Gene regulatory factors in pancreatic development. Dev Dynam 2004;229:176-200.

14 Dor Y, Brown J, Martinez OI, et al. Adult pancreatic beta-cells are formed by self-duplication rather than stem-cell differentiation. Nature 2004;429:41-46.

15 Seaberg RM, Smukler SR, Kieffer TJ, et al. Clonal identification of multipotent precursors from adult mouse pancreas that generate neural and pancreatic lineages. Nat Biotechnol 2004;22:1115-1124.

16 VanderGeer P, Hunter T, Lindberg R. Receptor proteintyrosine kinases and their signal transduction pathways. Annu Rev Cell Biol 1994;10:251-337.

17 Warburton D, Seth R, Shum L, et al. Epigenetic role of epidermal growth factor expression and signalling in embryonic mouse lung morphogenesis. Dev Biol 1992; 149:123-133.

18 Kornblum HI, Yanni DS, Easterday MC, et al. Expression of the EGF receptor family members ErbB2, ErbB3, and ErbB4 in germinal zones of the developing brain and in neurosphere cultures containing CNS stem cells. Dev Neurosci 2000;22:16-24.

19 Boockvar JA, Kapitonov D, Kapoor G, et al. Constitutive EGFR signaling confers a motile phenotype to neural stem cells. Mol Cell Neurosci 2003;24: 1116-1130.

20 Carver RS, Stevenson MC, Scheving LA, et al. Diverse expression of ErbB receptor proteins during rat liver development and regeneration. Gastroenterology 2002;123:2017-2027.

21 Noguchi H, Sakamoto C, Wada K, et al. Expression of heregulin alpha, erbB2, and erbB3 and their influences on proliferation of gastric epithelial cells. Gastroenterology 1999;117:1119-1127.

22 Oberg C, Waltenberger J, Claesson-Welsh L, et al. Expression of protein tyrosine kinases in islet cells: possible role of the Flk-1 receptor for beta cell 
maturation from duct cells. Growth Factors 1994;10: 115-126.

23 Press MF, Cordon-Cardo C, Slamon DJ. Expression of the HER-2/neu proto-oncogene in normal human adult and fetal tissues. Oncogene 1990;5:953-962.

24 Kritzik MR, Krahl T, Good A, et al. Expression of ErbB receptors during pancreatic islet development and regrowth. J Endocrinol 2000;165:67-77.

25 Miettinen PJ, Huotari M, Koivisto T, et al. Impaired migration and delayed differentiation of pancreatic islet cells in mice lacking EGF-receptors. Development 2000;127:2617-2627.

26 Kayali AG, Van Gunst K, Campbell IL, et al. The stromal cell-derived factor-1alpha/CXCR4 ligand-receptor axis is critical for progenitor survival and migration in the pancreas. J Cell Biol 2003;163:859-869.

27 Wagner M, Weber CK, Bressau F, et al. Transgenic overexpression of amphiregulin induces a mitogenic response selectively in pancreatic duct cells. Gastroenterology 2002;122:1898-1912.

28 Gmyr V, Kerr-Conte J, Vandewalle B, et al. Human pancreatic ductal cells: large-scale isolation and expansion. Cell Transplant 2001;10:109-121.

29 Bogdani M, Lefebvre V, Buelens N, et al. Formation of insulin-positive cells in implants of human pancreatic duct cell preparations from young donors. Diabetologia 2003;46:830-838.
30 Palmer HJ, Tuzon CT, Paulson KE. Age-dependent decline in mitogenic stimulation of hepatocytes. Reduced association between Shc and the epidermal growth factor receptor is coupled to decreased activation of Raf and extracellular signal-regulated kinases. J Biol Chem 1999;274:11424-11430.

31 Gennaro G, Menard C, Giasson E, et al. Role of p44/p42 MAP kinase in the age-dependent increase in vascular smooth muscle cell proliferation and neointimal formation. Arterioscler Thromb Vasc Biol 2003;23: 204-210.

32 Yi ES, Yin S, Harclerode DL, et al. Keratinocyte growth factor induces pancreatic ductal epithelial proliferation. Am J Pathol 1994;145:80-85.

33 Krakowski ML, Kritzik MR, Jones EM, et al. Pancreatic expression of keratinocyte growth factor leads to differentiation of islet hepatocytes and proliferation of duct cells. Am J Pathol 1999;154: 683-691.

34 Gao R, Ustinov J, Pulkkinen MA, et al. Characterization of endocrine progenitor cells and critical factors for their differentiation in human adult pancreatic cell culture. Diabetes 2003;52:2007-2015.

35 Ishiwata T, Friess H, Buchler MW, et al. Characterization of keratinocyte growth factor and receptor expression in human pancreatic cancer. Am J Pathol 1998; 153:213-222. 